\section{LA FIESTA PATRONAL DE \\ SAN GREGORIO ATLAPULCO, \\ MÉXICO. ESPACIO DE \\ REPRODUCCIÓN CULTURAL E \\ IDENTITARIA}

\section{Resumen}

En medio de un escenario desolador para el campo mexicano, encontramos alternativas de resistencia y de recuperación del patrimonio histórico, económico, natural y cultural de los pueblos rurales, originarios, que se asientan en el sur de la Ciudad de México.

De manera particular, las fiestas religiosas contrastan con el momento histórico, donde la situación mexicana actual suele caracterizarse a partir de la pobreza el desempleo, la inseguridad y la desarticulación social.

En el pueblo de San Gregorio Atlapulco, la celebración de su santo patrono es una forma de hacer perdurar las tradiciones centenarias. En la fiesta encontramos elementos culturales que han resistido los embates del colonialismo, de la modernidad y de la urbanización.

Palabras clave: Santo patrono, resistencia cultural, tradición, pueblo originario

\section{Summary}

In the middle of a crisis in Mexican's rural area, native communities located in the southern part of México City find an alternative in cultural resistance and in the recuperation of historic, economic, natural and cultural heritage.

In particular, there is a contrast between religious feasts and the current historical moment, where Mexican situation is often characterized through poverty, unemployment, insecurity and social dislocation. 
Inthevillage ofSan Gregorio Atlapulco, thecelebration of theirlocal patronsaintisa waytoendurecenturies-oldtraditions. Inthecelebration, wefind culturalelements that have withstood the ravages of colonialism, modernity and urbanization.

Keywords: Patron saint, cultural resistance, tradition, native communities

\section{INTRODUCCIÓN}

- $n$ medio de un escenario desolador para el campo mexicano, encontramos - alternativas de resistencia y de recuperación del patrimonio histórico, económico, natural y cultural de los pueblos rurales, originarios, que se asientan en el Distrito Federal.

Para el caso específico de la zona de Xochimilco, consideramos que a pesar de las condiciones adversas atribuidas a una crisis, que lejos de detenerse parece conducir a la deriva, existen alternativas que nos llevan a centrar la mirada en otras formas de enfrentar la cotidianidad, de establecer los vínculos sociales y revalorar las prácticas que culturalmente le dan sentido a lo local. De manera particular, las fiestas religiosas contrastan con el momento histórico, donde la situación mexicana actual suele caracterizarse a partir de la pobreza el desempleo, la inseguridad y la desarticulación social.

En el pueblo de San Gregorio Atlapulco, la celebración de su santo patrono es una forma de hacer perdurar las tradiciones centenarias. En la fiesta encontramos elementos culturales que han resistido los embates del colonialismo, de la modernidad y de la urbanización.

Es muy conocido cómo los migrantes, nacionales e internacionales, suelen regresar a su lugar de origen durante las fiestas patronales, o reproducir en sus nuevos espacios su fiesta. Y cómo no habría de ser así, si el día de las fiestas, los rostros se reconocen, los lazos de pertenencia se refrendan, se apropian los espacios públicos, se defiende el derecho a la alegría. En palabras de Cenobia Santa Eslava:

Venimos a formar una trinchera contra los graves diagnósticos de nuestra realidad, venimos a unirnos contra la infamia y los infames que en aras del progreso quieren borrar nuestro rostro o nos quieren vender como alegorías turísticas. Venimos a formar cuerpo contra nuestra propia devastación y a inventar la nueva grafía de esta celebración que da significadoyhonraanuestropuebloyanuestrosancestros(Eslava, 2010:87).

Como dice Parker "La cuestión cultural de hoy se plantea en el marco de dos tendencias contradictorias y mutuamente necesarias: la globalización y la persistencia de las identidades locales" (Parker: Alteridades, 2006,89).

A partir de lo anterior, el presente trabajo revisa la fiesta patronal a San Gregorio no sólo como una celebración, ocasión de encuentro, sino de organización comunitaria y sustrato de identidad, para cuestionar: ¿hasta dónde estas fiestas son símbolo de resistencia cultural, frente al proyecto modernizador $y$ al crecimiento de la gran metrópolis?, ¿qué tanto cumplen una función de cohesión comunitaria y de adscripción identitaria?, ¿en qué medida la fiesta recupera el patrimonio histórico, natural, cultural y social local?

\section{San Gregorio Atlapulco}

San Gregorio Atlapulco es un pueblo del sur de la Ciudad de México, absorbido por la mancha urbana, pero en donde aún persisten actividades agrícolas, acompañadas por una cultura rural, con una identidad y prácticas sociales que muestran una cierta resistencia a las formas y costumbres urbanas de la zona metropolitana en la cual están inmersas.'

Destaca el sistema de cultivo característico del lugar, la chinampa, una práctica heredada desde los tiempos precolombinos y que ha sido valorada y reconocida en términos de patrimonio ecológico, tanto por instancias oficiales nacionales e internacionales, como por organizaciones locales ${ }^{2}$.

1 A nivel internacional, en 1987, Xochimilco fue reconocido por la UNESCO como patrimonio de la humanidad; en el ámbito nacional, en 1992, se declara a los Ejidos de Xochimilco y a San Gregorio Atlapulco comoárea natural protegida, bajola categoría de Zona sujeta a Conservación Ecológica y en el local hay asociaciones como el Grupo Tiempo y Agua, que se preocupan por el rescate de la chinampa como uno de los símbolos territoriales de gran valor.

2 A nivel internacional, en 1987, Xochimilco fue reconocido por la UNESCO como patrimonio de la humanidad; en el ámbito nacional, en 1992, se declara a los Ejidos de Xochimilco y a San Gregorio Atlapulco comoárea natural protegida, bajo la categoría de Zona sujeta a Conservación Ecológica y en el local hay asociaciones como el Grupo Tiempo y Agua, que se preocupan por el rescate de la chinampa como uno de los símbolos territoriales de gran valor. 
La chinampa tiene su riqueza en la particularidad que representa como sistema agrícola y en que, a pesar de la resistencia frente a lo urbano, no se aísla, sino que establece vínculos. El lugar abastece de hortalizas y plantas de ornato a la Ciudad de México. Sus campesinos van a vender a la Central de abastos; muchas veces combinan su actividad productiva con otras que realizan y que son de corte más urbano. Algunos de sus pobladores incluso se hicieron profesionistas y otros, después de jubilarse, volvieron a trabajar el campo (Landázuri y López Levi, 2011). Antes el campo pertenecía a los más viejos, pero ahora, ante la crisis, los jóvenes se han reincorporado a la siembra.

Las prácticas productivas se han adaptado al deterioro ambiental. Antes no era necesario regar las tierras y ahora hay que bombear agua de los canales para los cultivos. San Gregorio también es un lugar de innovación, pues se han desarrollado una serie de ecotecnias propias del lugar (Landázuri y López Levi, 2011)

El nombre de San Gregorio Atlapulco encierra los dos elementos centrales de la identidad del pueblo: la fiesta en honor a su santo patrono San Gregorio Magno y su tradición agrícola que se expresa en la palabra Atlapulco, "donde revolotea el agua" o en "las tierras del fango"

Las prácticas religiosas locales se insertan a nivel regional en el ámbito de Xochimilco, una zona predominantemente católica, donde la religiosidad popular tiene una fuerza que emana de sus propios pobladores; de sus habitantes que hacen suyas las tradiciones seculares y las viven en forma festiva, de acuerdo a costumbres que se han fincado por generaciones.

La Iglesia Católica, desde su establecimiento en la región, sentó las bases de la organización territorial para diversos aspectos de la vida social y cultural de sus habitantes. En Xochimilco, aunque se registra un descenso en la población que se asume parte de esta religión, el INEGI a través del Censo de Población y Vivienda señala actualmente la existencia de casi un $85 \%$ de población católica (INEGI, 2010).

En lo local, las prácticas religiosas retoman las costumbres que por siglos han prevalecido y le dan una singularidad a la forma como éstas se expresan.

1 El primero registrado en la tesis de Gladys Sirvent y el segundo mencionado por un Coordinador territorial del lugar.
Los ritos, la música, los bailes, la comida, los fuegos artificiales y todo lo que compone la fiesta reflejan la organización socio territorial y tiene repercusiones más allá del ámbito religioso y forma parte de la vida cotidiana. Se dice que en Xochimilco todos los días del año son una fiesta. Si no es el santo patrono de uno de los barrios o pueblos, es alguna virgen o algún Niño Dios, entre los que destaca el NiñoPa. Cada una de las imágenes tiene actividades a lo largo del año; hay misas, visitas, son llevadas a ver a los enfermos, encabezan las procesiones. En fin, que en su honor siempre hay un ambiente festivo.

Aunque en el presente texto nos centramos en la fiesta patronal de San Gregorio Atlapulco, no podemos dejar de reconocer que el carácter de la cultura popular religiosa hace de dicho espacio un lugar de fiesta continua, donde siempre hay algo que conmemorar o alguna imagen que venerar. Destacan en la localidad los festejos de semana santa, en marzo-abril, cuando los jóvenes varones, uno de los principales grupos religiosos de la localidad, organizan el Vía Crucis. "Algunas veces hacen estaciones en capillas o cada quien en su barrio. Se acostumbra la visita de las siete casas. Se lleva al Santísimo, se hace una velación hasta la una de la mañana" (Landázuri et al, 2006). Están también las celebraciones de la Virgen de Guadalupe durante todo el mes de diciembre, el primero de enero y todo el mes de mayo; la celebración a la Virgen de la Asunción, el 15 de agosto; el día de muertos; el jubileo parroquial en diciembre; la celebración del Santísimo; las posadas, la Navidad y los pequeños festejos en cada una de las casas que reciben a las imágenes o a los miembros de algún comité, después de sus labores para colaborar con la fiesta.

\section{La religiosidad popular}

De acuerdo con María Ana Portal (1999:20), la religiosidad popular engloba una serie de prácticas sociales que enlazan elementos católicos con elementos ancestrales de Mesoamérica, en particular con una expresión social vinculada a un sistema de cargos o mayordomías que articulan la vida social y la identidad comunitaria. Dichas prácticas norman sobre la participación social, de manera tal que se convierten en formas de cohesión, pertenencia y anclaje territorial.

De tal manera que podemos considerar que las fiestas religiosas y en forma destacada, la del santo patrono, son un elemento central de la organización social, un factor de vitalidad local, una forma de reproducción del sentido comunitario y un componente clave en la identidad cultural y el arraigo territorial. La fiesta se convierte en un mecanismo de resistencia cultural por 
parte de los llamados pueblos originarios; un instrumento, por medio del cual le dan continuidad a sus tradiciones, sus valores, sus formas de organización social, de vinculación con la naturaleza y su memoria histórica.

Gilberto Gimenez (citado por Portal, 1999:21-22) coloca al santo patrono como elemento central de la organización social, que es principio vital de la comunidad y clave de la identidad. En él convergen las relaciones sociales materializadas en el sistema de cargos y mayordomías. Además, es la confluencia de un ancestro mítico del pueblo; condensa una historia y fija un origen común que sintetiza elementos prehispánicos con los derivados de la colonia española. La reproducción anual de la celebración en su honor es una forma de recreación de las fronteras territoriales y de las redes de relaciones sociales. Las fiestas implican reciprocidad frente a otros santos.

La estructura social que sustenta la reproducción cultural está fuertemente apoyada por el sistema de cargos, que Portal (1999: 22) define como "una institución cívico-religiosa, altamente jerarquizada, característica de las formas organizativas de grupos indígenas que hoy ocupan el área de Mesoamérica, particularmente entre aquellos grupos indígenas contemporáneos". Aunque las mayordomías se articulan en torno a la fiesta, la trascienden en términos de sus implicaciones soci-territoriales. La sociabilidad en Xochimilco, afirma Víctor Manuel Durand (2010: 174) "está basada en la familia y el barrio".

Si bien quienes ocupan estos cargos son nombrados individualmente, la pareja y la familia ampliada son las que generalmente asumen el compromiso de mayordomos, posaderos y miembros de los comités de feria. Las tareas van desde velar por la imagen y organizar la fiesta, organizar peregrinaciones, ofrecer comida cuando se asume el cargo, se recibe al santo o cuando se hace alguna velación, hasta atender a los visitantes. Es así como se establecen redes y vínculos entre los miembros de la comunidad y con los de los otros pueblos.

En este sentido, su individualidad queda subsumida a las prácticas y decisiones comunitarias. La población participa siguiendo las reglas tradicionales (Durand, 2010: 204). Las fiestas se desarrollan en las calles, en las plazas, en los parques, explanadas y en las casas.

La reproducción del espacio se fundamenta en la identidad. Los originarios se reconocen como pertenecientes a un lugar cuya toponimia hace referencia a su Santo Patrono, son herederos de una tradición histórica, de modos de vida y de una pertenencia territorial. Se distinguen frente al otro, al avecindado, el que no es de ahí, el extranjero.

Aunque existen excepciones, la comunidad en su conjunto participa. De acuerdo con Lima (2001:123) es a través del culto que se despliegan las formas de participación ciudadana, así como de fortalecimiento de las relaciones sociales y familiares. "Este culto promueve que las calles, los panteones y los patios de las casas se conviertan en grandes plazas públicas de encuentro y convivencia, en grandes templos para el ritual sincretizado."

La relación con las autoridades permite la celebración de las fiestas, el cierre de calles y la apropiación del espacio público. La tradición, afirma Durand (2010: 205) se impone al derecho formal. El permiso no se basa en la ley escrita, sino en la voluntad de no contrariar a la comunidad que defiende, ante todo, sus prácticas tradicionales.

Dichas tradiciones le otorgan a la comunidad una cohesión fundamentada en la solidaridad. Es por ello que la dinámica va más allá de un grupo de fieles que manifiesta su religiosidad. Se trata de una comunidad que reivindica sus prácticas sociales y la forma como se insertan dentro de la vida de la gran ciudad.

\section{La expresión de religiosidad popular en las fiestas}

Desde que se estableció la iglesia católica en Xochimilco sentó las bases de su organización territorial y administrativa que permeó la vida social y cultural de los pobladores. En Xochimilco, la evangelización de los indígenas fue obra fundamentalmente de los franciscanos en los siglos XVI y XVII, por lo que los principales templos datan de esos siglos ${ }^{12}$.

A cerca de 500 años de evangelización, la resistencia que desde los primeros años de la conquista permitió imponer algunos rasgos del calendario ritual prehispánico, de las formas de culto y celebración a las deidades, así como de ciertas formas de organización y cohesión comunitaria persisten a pesar del proyecto modernizador y al crecimiento de la gran metrópolis. La resistencia

2 El templo de San Gregorio Atlapulco data del siglo VII y contó con un convento desde donde se realizó la tarea evangelizadora (Pérez, J.M.,2003:21) 
cultural a partir de la permanencia de rituales y tradiciones que remiten a los antepasados, y a una forma de organización comunitaria que fortalece lazos de identidad.

El contraste entre las celebraciones prehispánicas a las deidades llenas de regocijo, de ofrendas a los dioses para pedir un buen año, fertilidad y buena producción, en las que abundaban vistosos atuendos, manjares, danza, música, y un ambiente festivo, se hacen patentes en estudios como el de "Religiosidad y Ciudadanía en Xochimilco.

La fiesta de Xaltocan" de Cenobia Santa Eslava Martínez, nos muestran. Al igual que para este caso, en San Gregorio Atlapulco la parte festiva no sólo sigue acompañando la conmemoración al santo patrono, sino que es parte central de la misma.

La combinación de una expresión católica con tintes prehispánicos se puede rastrear hasta los tiempos de la conquista y colonia, cuando de acuerdo con Pérez (2003: 23), los cronistas reconocieron que la conversión, aparentemente voluntaria, de los indígenas al cristianismo obedeció en el fondo a una estrategia de adaptación para continuar con sus ritos y ceremonias. "No muy tarde los frailes se darían cuenta que de atrás de aquellos actos de devoción espontánea pervivían los antiguos dioses prehispánicos" (Pérez, J.M., 2003:23). Entonces, denunciaron que esas formas paganas habían invadido las celebraciones católicas. Sus ecos llegaron al presente. En la actualidad algunos curas se expresan de la misma forma sobre las fiestas patronales y afirman que en ellas "hay mucho ruido".

El sincretismo religioso de estas dos culturas aún se manifiesta en muchas localidades rurales del país y ha sido analizado desde diversos enfoques. En términos generales se ha entendido principalmente como religiosidad popular, sin embargo, algunos autores como Vania Salles y José Manuel Valenzuela lo llaman mística popular subalterna' y lo aborden a partir de considerarlo como una vida espiritual que va más allá de lo religioso, con gran cantidad de relaciones con lo supranatural y, en donde se incorporan hábitos en las prácticas cotidianas fuertemente ligados a las tradiciones. Algunas de ellas de corte prehispánico. Por su parte, Manuel Antonio Baeza (2000:98-99) habla

1 Para ellos los popular "se aplica a ese sector difuso de la población que no ocupa los estratos altos de la estructura social, ni controla los mecanismos de poder y de coerción macroinstitucionalizados" (Salles y Valenzuela, 1997:60-61) de cultura popular religiosa y afirma que se trata de la religión en su vertiente no oficial, en tanto que es simple, que no pone restricciones a las formas de emoción y que se acerca a la espontaneidad del cristianismo primitivo.

Dicha cultura es en esencia heterogénea y está compuesta por una gran diversidad de imaginarios de lo religioso, mismos que se generan a partir un lugar y un momento concretos; se producen con base en los valores, las tradiciones, los conocimientos, trayectorias, prácticas sociales y el entorno de cada comunidad, para después reflejarse, materializarse y representarse de múltiples formas, entre estas, nosotros destacamos la fiesta como un espacio socializador de reproducción de creencias colectivas basadas en esas tradiciones, de cultura y de identidades.

A los franciscanos se atribuyen muchas de las tradiciones religiosas que existen hoy en día en Xochimilco, las cuales sobreviven por el apego de los pobladores a las costumbres heredadas por sus ancestros.

En la actualidad, la comunidad se ha apropiado de las fiestas religiosas en Xochimilco y los miembros de la jerarquía católica tienen ya muy poca participación. Los fieles laicos se encargan de la organización, para lo cual se estructuran en torno a las mayordomías y a una serie de comisiones encargadas de los distintos aspectos relacionados con los festejos, como lo son, la recaudación de dinero para el alquiler de templete y lonas, la contratación de las bandas de música y equipo de sonido, los cuetes y castillos.

El origen de las estructuras de cargos y prácticas de las mayordomías se remontan a la Corona Española, cuando se adoptaron algunas de estas disposiciones. Las cofradías introducían a los nativos a la devoción de un santo e intentaban acercar a los fieles a la Iglesia católica, no sólo en función de la fe sino también para cubrir una función económica, administrativa. Ambas funciones estaban a cargo del "Mayordomo", es decir, el cuidado del santo y la recaudación y administración de bienes de la cofradía. Los primeros en ser nombrados mayordomos fueron los caciques con más propiedades; de tal manera que se creaba un mecanismo para que el clero accediera a sus bienes. También "se autorizaba hacer colectas a manera de limosnas para pagar los gastos en ceras, flores, procesiones, misas y todo lo que exigió el culto al santo de su devoción" (Eslava, 2010:42).

Para los indígenas estos espacios resultaron espacios de "libertad", de cohesión, 
en torno a los cuales compartían sus "antiguas prácticas religiosas, estilos de vida, sentido de pertenencia" (Eslava, 2010:43).

Eslava (2010:43) afirma también que esta estructura ha sido la base de la "resistencia cultural que hasta la fecha se mantiene viva en Xochimilco."

\section{Organización y solidaridad en las fiestas religiosas}

En la esfera social, las fiestas constituyen espacios para la integración. La tradición que mantiene estas prácticas está envuelta por la fe y también representa la unión y solidaridad entre muchos de los habitantes de Xochimilco. Este tipo de festejos se desbordan en organización, participación, colaboración, cohesión comunitaria y nos preguntamos cómo es que en otros espacios se aduce tanto que no hay organización ni participación ciudadanas. Y es que la fiesta, no es fiesta de un día, y sólo una misa se prolonga por semana, en un sinfín de actividades religiosas en los barrios, así como actividades festivas en las que abundan grupos musicales, se requiere logística, financiamiento, difusión, amplia coordinación de diversas comisiones y toma de decisiones.

Estas manifestaciones muestran "la existencia de identidades culturales de índole religiosa que- a pesar de la modernización y de los procesos de secularización en ella implicados se reproducen mediante un conjunto de instancias socializadoras" (Salles y Valenzuela, 1997: 15) como son las fiestas. Para Salles y Valenzuela no se trata solamente de la reproducción de una herencia del pasado, "de ritos y ceremonias vinculados a cosmovisiones y construcciones simbólicas del pasado" (Salles y Valenzuela, 1997: 18), sino también de prácticas actualizadas y ajustadas a su entorno contemporáneo.

En las fiestas contrastan los elementos sacros y profanos, los contemporáneos y tradicionales los institucionales y populares de integración y resistencia cultural. Contribuyen a la construcción de un orden social.

Frecuentemente se pide a la comunidad colaborar con los gastos de estas fiestas, recibiendo respuesta positiva de la mayoría de las familias quienes llegan a aportar $\$ 200$ y hasta $\$ 500$. En algunos templos se tiene la costumbre de exhibir la lista de las familias que sí aportaron.

\section{Las fiestas religiosas en San Gregorio}

La religiosidad popular en San Gregorio Atlapulco, aunque tiene sus matices locales, está inmersa en la dinámica cultural de Xochimilco, donde las tradiciones católicas, transmitidas originalmente a través de los franciscanos que llegaron durante la colonia, se combinan con las costumbres heredadas por los ancestros prehispánicos de sus pobladores.

Las fiestas religiosas locales, aunque convergen en la Iglesia, están organizadas por los fieles laicos, quienes se organizan en mayordomías y en comités. El párroco y otros miembros de la iglesia participan, están presentes, pero no tienen la celebración en sus manos. Dichos comités se encargan de la recaudación de fondos y de la organización del festejo. Son varios y se avocan a distintos aspectos, la música, los cohetes, los bailes, el templete y las lonas, entre otros.

Los mayordomos tienen la función de mantener el rito religioso y son los depositarios, por un tiempo determinado, de una imagen . En San Gregorio existen mayordomos para cada una de las imágenes importantes a nivel local. La función implica grandes compromisos que conllevan mucho dinero, ahorrado durante años. A cambio, los encargados obtienen distinción y prestigio social. Se trata de una figura comunitaria, independiente de la Iglesia, pero que confluye con ella en términos de lo que se venera.

Los mayordomos custodian el altar, se encargan de la limpieza y mantenimiento de la iglesia, se rotan el cuidado de la imagen mensualmente, solicitan la cooperación para las celebraciones y organizan diversos rituales, como son velaciones, rosarios, peregrinaciones, según sea el caso'.

El mayordomo tiene un estatus social y un prestigio que se construye a partir de su participación religiosa y no tiene relación con su ocupación o modo de vida. Es una figura pública que se apoya en sus redes sociales, en particular en su familia, estrecha y ampliada. Algunos de cuyos miembros tienen funciones de apoyo, como es el caso de los posaderos. Estos puestos pueden ser asumidos individualmente, sin embargo, son ejercidos familiarmente (Salles, 1995).

El 2 de febrero, durante la ceremonia del día de la Candelaria, se da el cambio de

1 Hay 7 imágenes o altares: el santísimo, la virgen de Guadalupe, el Sagrado corazón, la Purísima, los Varones, la Candelaria, la virgen del Carmen, la Hermandad. Están también el Niño del pueblo. niños de los barrios (hay alrededor de 30 barrios en San Gregorio Atlapulco), nueve o 10 nichos del señor de Chalma y también reciben al Niño Pa. 
mayordomos. Los nuevos encargados son coronados por el párroco y además se hace la entrega de "la luz de la Biblia". Este es un día muy importante en la localidad. Los diferentes barrios salen para venerar al Niño Dios y lo llevan en peregrinación a otras localidades de Xochimilco (Landázuri et al, 2006). Ese día los productores también llevan a bendecir las semillas (Landázuri y López Levi, 2011).

La fiesta de la Candelaria en la que se presenta al niño Jesús en el templo coincide con numerosos rituales prehispánicos en los que los actores principales eran los niños que representaban el inicio de la vida humana. El dos de febrero era el inicio del calendario Mexica. Esto muestra cómo el proceso de sustitución religiosa no sólo se construyó sobre los antiguos templos, sino también sobre los antiguos símbolos. Por cierto, en esa fecha también se bendicen las semillas, ahora más bien simbólicamente, rememorando esa práctica, que puede remontarse a varios siglos.

El calendario religioso le da una estructura temporal a este complejo sistema cultural, en donde se engarzan elementos de identidad, arraigo y organización social. Hay múltiples festejos religiosos a lo largo del año que involucran rituales, organización, etc. Si en Xochimilco se dice que 365 fiestas al año, San Gregorio Atlapulco no se queda atrás.

Se refrendan así dinámicas comunitarias propias de espacios rurales, de comunidades indígenas, de allí que se les denomine pueblos originarios, comunidad laicas que se reafirman en torno a la "festividad - culto religioso", la llamada religiosidad popular.

La fiesta patronal es el día 12 de marzo. Sin embargo, es costumbre que se traslade al domingo más próximo, para considerar a la población que trabaja entre semana y asegurar que puedan participar de la celebración. A diferencia de muchos otros lugares en que se celebra al santo el día en que aparece en el calendario litúrgico, en este pueblo se celebra la muerte de San Gregorio Magno. Después, el 3 de septiembre, el día de San Gregorio Magno en el santoral católico, también se celebra al Santo Patrono, aunque la fiesta es más sencilla que la anterior ${ }^{1}$. El hecho de que la fiesta a San Gregorio sea el 12 de marzo ha sido vinculado con las celebraciones y rituales de épocas prehispánicas. Algunos estudiosos de la historia local como Roberto Paez y Jaime Tirso Pérez

1 Por iniciativa de uno de los párrocos hace unos 15 años.
Venancio sostienen que este periodo coincidía con las fiestas a la fertilidad o con festejos a a la diosa Xiloen (Diosa de los elotes tiernos) o Chicomecoatl (Diosa de las mieses y de todo género de simientes y legumbres). Lo que es un hecho es que el sincretismo se expresa de múltiples maneras, con las danzas de los aztecas y los concheros, con el ambiente festivo que la acompaña. Muestra de ello, es que durante una entrevista, al preguntarle a uno de los concheros más antiguos a quien dirigen sus alabanzas, nos respondió que además del Santo, a Tláloc.

\section{Organización de la fiesta patrona}

La fiesta patronal de San Gregorio Atlapulco es una celebración que pertenece al pueblo, más que a la iglesia, y es el pueblo quien define autónomamente la manera de festejar al santo patrono. Es un momento de encuentro de los atlapulquenses, con los familiares que han emigrado, con los amigos y compadres de fuera, consigo mismos. Si bien, algunas iglesias no católicas prohíben la participación en este festejo de religiosidad popular católica, algunos de sus miembros siguen colaborando, y participando en esta fiesta que además de expresar una identidad religiosa, expresa la pertenencia espacial y cultural. En palabras del Párroco de San Gregorio, Antonino Zepeda Salazar, se organiza de la siguiente forma que:

En esta fiesta patronal del mes de marzo, hay a mi entender dos líneas de organización, 1) que sería desde el interior de la iglesia a través del equipo pastoral parroquial, que vamos organizando todo el aspecto litúrgico celebrativo, y la $2^{a}$ es lo que podría llamarse la fiesta desde el punto de vista externo, pues existe un comité de feria, ese comité está organizado de forma autónoma a la parroquia (Entrevista Párroco Antonino Zepeda Salazar).

Con el objeto de venerar a su santo patrono, la población se organiza, se divide en diversos grupos y comités que definen las actividades, las patrocinan y las organizan, considerando tanto la ceremonia religiosa como las actividades festivas.

Entre estos destacan los grupos pastorales, quienes organizan junto con el párroco el calendario de misas que se celebrarán a lo largo de una semana (la octava), en los que habrán de participar ellos, los encargados de los diferentes altares a lo largo del año y los grupos de los barrios. 
Otro grupo importante es el de los mayordomos del Santísimo, quienes cumplen una función de coordinación en las actividades dentro de la Iglesia: la vigilancia, las flores, la limpieza. No hay un mayordomo encargado de la fiesta patronal, pero sí muy diversos grupos de fieles laicos, que se organizan para financiar una serie de acciones: las portadas internas y externas, piezas de creatividad que anualmente se renuevan, la música que se ofrece a San Gregorio, al interior y exterior del iglesia, y un sinnúmero de actividades festivas, como son las bandas norteñas, las bandas sinfónicas, las danzoneras, la pelea de gallos, el jaripeo, etc

En el Comité de feria participan representantes de los diversos grupos y entorno a ellos se aglutinan lechugueros, chinamperos, músicos, bandas y danzantes, entre otros.

La música de mariachis está a cargo del grupo 12 de marzo, quienes independientemente del día de inicio de las fiestas, en el día de San Gregorio (fecha que le da nombre al grupo) ofrecen música, tanto al interior del templo, como en el atrio. Al evento asisten cientos de habitantes de San Gregorio Atlapulco. También hay otras bandas como la banda borracha y la banda sonrisas infantiles.

A los anteriores, se unen los danzantes aztecas y los concheros tanto de San Gregorio Atlapulco cómo los que vienen a pagar mandas o promesas de pueblos vecinos o amigos. Queda patente en sincretismo de estas fiestas, en esta religiosidad popular en las que las fuerzas de los antiguos rituales, con sus trajes, danzas y representaciones se sigue manifestando al igual que se hacía "frente a los ojos de los religiosos franciscanos, que veían en ello una forma distinta y tolerable de honrar a la divinidad" (Pérez, J.M., 2003:21).

Están también los santiaguitos que hacen una representación teatral que rememora el teatro franciscano utilizado como recurso de conversión religiosa, el grupo danzante de los vaqueritos. Un grupo que era muy característico de San Gregorio Atlapulco era el de las pastoras, que ya no se ha presentado en los últimos años. Todas estas actividades se realizan en el atrio de la iglesia.

También están los comités que organizan la colecta para las salvas, los castillos, los conciertos y los bailes. Todas estas actividades son ofrendas al santo patrón, generalmente presididas por misas a las que asisten los organizadores y colaboradores. Algunos de estos grupos están vinculados con los lechugueros y chinamperos, miembros de la sociedad agraria que aún existe en San Gregorio Atlapulco. Por ejemplo, Fernando Márquez, del grupo de los chinamperos, quien nos explica la fiesta patronal como una forma dar gracias, ya que nos ha ido bien en el campo o que no nos ha dado mal tiempo.

Contratamos un artista, es la forma de agradecer o pedir favores.

La colaboración voluntaria va desde 50 pesos hasta miles de pesos, para costear todas estas actividades. Esto nos habla de una identificación colectiva de esta celebración.

El día de fiesta principal, por la noche, se queman castillos, organizados territorialmente en la primera y la segunda manzana; en una estructura espacial definida desde la época de la colonia, que sirve de base para una competencia por quien presenta el mejor castillo.'

A lo largo de la semana se organizan diversos eventos festivos: conciertos, espectáculos infantiles, bailes tanto en el atrio de la iglesia como en la plaza cívica a espaldas del templo, bajo la coordinación del Comité de feria. Entre otras cosas están los juegos mecánicos, los puestos de comida, y otras atracciones típicas de las ferias populares. El derecho de piso se cobra, y representan prácticamente los recursos económicos que el Comité de feria recaudará, las "ganancias de las fiestas". Estos recursos han tenido diferentes usos muchos relacionados con el mantenimiento y ampliación de la Iglesia, reposición de la campana y en los años recientes se ha buscado invertirlos en actividades comunitarias, como en la fiesta del día de las madres y en el día del niño. Esto muestra la posibilidad de que la organización comunitaria en torno a las celebraciones religiosas puede trascender esos momentos.

En entrevista a los presidentes de los comités de feria de los dos últimos años, los dos expresaron su orgullo de que las fiestas, tanto del 12 de marzo como del tres de septiembre, son autofinanciadas por la comunidad. Sólo piden apoyos de infraestructura y servicios a la delegación de Xochimilco, en los rubros de seguridad, vialidad, servicio de limpieza y recolección de basura, se aprovecha para solicitar la reparación o sustitución de luminarias, transformadores y

1 Como dato de la derrama económica de la fiesta, baste decir que cada castillo cuesta alrededor de 190.000 pesos. 
lonas para los puestos de diversos giros.

Por último, como sucede en una fiesta, además de la convivencia comunitaria, en el seno familiar también se festeja, preparando principalmente los platillos típicos de la localidad: pollo con mole y tamalitos de frijol. Allí se reúnen con la familia, los amigos, los invitados externos, o sea todos están de fiesta.

En síntesis, que en la fiesta patronal, el pueblo de San Gregorio Atlapulco se vuelca en los bailes, castillos, música y juegos, que organizan los del comité de feria. La localidad se divide en dos sectores y ambos se organizan para los fuegos artificiales y para el concurso de los mejores castillos. Hay grupos que se encargan de la salva, del grupo de castilleros y de la contratación de las bandas. Además, hay un coordinador de feria que también trabaja independiente de la parroquia y organiza los puestos que se ponen en la calle durante la semana previa y la posterior al domingo más cercano a la fecha (Landázuri et al, 2006).

\section{Redes familiares y cohesión comunitaria}

Estas formas de organización socio-religiosa de la comunidad, de acuerdo a María Ana Portal y Cristina Sánchez Mejorada (2010), se asientan en la estructura del sistema de cargos y del sistema de parentesco. Se construyen así redes familiares basadas en la reciprocidad, tanto al interior como a exterior del pueblo, que generan "el derecho de pedir y la obligación de dar.... estos mecanismos de reciprocidad y solidaridad anclados en el parentesco que adquieren su particularidad en función de factores económicos, sociales, históricos, etc., lo que se constituyen una de las estrategias culturales fundamentales para construir reproducir los vínculos con la ciudad" (Portal y Sánchez, 2010:121).

En San Gregorio Atlapulco anualmente cientos de parejas están involucradas en el cuidado, organización del culto a diferentes santos. Estas parejas recurren a la familia ampliada, a las amistades, a los vecinos para que acudan y apoyen la celebración. Por ejemplo, en el cambio mensual de mayordomos del Niño del pueblo, después de la misa se realiza un recorrido por las calles principales del pueblo, hasta la casa del mayordomo que recibe ese mes al niño, quien ofrecerá una comida a todos los asistentes. Para preparar y servir la comida recibe el apoyo de los familiares, especialmente las mujeres (hermanas, madres, hijas) y en muchos casos vecinos y amigos aportan algunos ingredientes y recursos para su preparación. Estas comidas pueden recibir decenas o cientos de comensales.

Esta estructura socio- religiosa a partir de núcleos parentales fortalece las identidad, el reconocimiento mutuo, de su pertenencia y apego a este lugar.

\section{Conclusiones:}

En un tiempo de crisis, donde la modernidad deja de ofrecer la posibilidad del progreso, las tradiciones, muchas veces investidas de religión constituyen el contrapeso, que le da sentido a la vida, la comunidad y el territorio. Es por ello que, siguiendo a Gimenez, consideramos que la religiosidad popular entendida como un conjunto de prácticas simbólicas colectivas que producen y reproducen sentidos sociales, es un contrapeso frente a la pérdida del sentido de la modernidad.

Para el caso de San Gregorio Atlapulco, a pesar de haberse insertado en dichos procesos de urbanización y profesionalización, la religiosidad popular sigue siendo un instrumento de cohesión social que atraviesa la cotidianidad temporal, espacial, personal y comunitaria.

Hablamos de la fiesta como un mecanismo importante para la resistencia cultural, ya que permite la recuperación de la memoria histórica, de los valores, las tradiciones y las formas de vida de la comunidad, mismas que constantemente se ven vulneradas por aquellas promovidas y en ocasiones impuestas por la lógica colonial, la seguida por la expansión física de la ciudad, la que adopta el proyecto modernizador y la que sigue el sistema capitalista actual.

La religiosidad popular es una forma de resistencia en cuanto a que ha significado la permanencia de tradiciones de origen prehispánico, así como de las formas de organización comunitaria.

Las prácticas culturales que se derivan de la fiesta como forma de reproducción cultural e identitaria reflejan que la comunidad es más importante que el individuo; que lo sagrado y lo profano están íntimamente relacionados. Lo anterior se hace patente cuando en otros ámbitos de la vida cotidiana, la cohesión no tiene tanto sentido y, por tanto, la organización social orientada a propósitos tales como el político o el productivo, no es tan elaborada, estructurada ni duradera, como lo es la de la fiesta. 
Para los pobladores de San Gregorio Atlapulco, el desarrollo no está en función de la economía, y el bienestar tiene que ver con una satisfacción espiritual, más que otro tipo de prácticas típicas de los modelos del capitalismo actual y de la mentalidad urbana. En este sentido, la estructura social es diferente, de manera tal que en el ámbito rural, la resistencia cultural, en la forma como la hemos analizado, no se limita a las clases subalternas o de bajos niveles de escolaridad; se trata de la defensa de tradiciones que responden a otro tipo de valores, a lo local, lo originario, lo católico.

La resistencia cultural se configura, como dijera Baeza, a partir de la construcción de un espacio socializador que permite reproducir las creencias colectivas basadas en esas tradiciones, de cultura y de identidades. $Y$ la religiosidad popular le da cohesión y fuerza a la comunidad, y, como dice Eslava, "eso explica su resistencia al deterioro: ha sido, entre otros valores culturales en los pueblos originarios, un sólido bastión para resistir los embates del tiempo y de la historia como: la conquista, la colonización, las guerras, las revoluciones, la influencia de una cultura occidental uniformadora" (2010:138).

\section{Bibliografia:}

- Baeza Manuel Antonio (2000) Los caminos invisibles de la realidad social. Ediciones Sociedad Hoy. RiL editores. Chile.

- Durand, Victor Manuel (2010) Desigualdad social y ciudadanía precaria. UNAM/ Siglo XXI Editores. México.

- INEGI (2010) Censo de Población y Vivienda 2010 [En línea] http:// www3.inegi.org.mx/sistemas/iter/entidad_indicador.aspx?ev=5 Instituto Nacional de Estadística, Geografía e Informática.

- Landázuri, Gisela et al (2006) Diversidad religiosa en Xochimilco. Universidad Autónoma Metropolitana/ Delegación Xochimilco. México.

- Landázuri, Gisela y López Levi, Liliana (2011) "El campesinado, entre lo local y lo nacional” en: Actores sociales, dinámicas locales. Eón Sociales/ Universidad Autónoma Metropolitana. México.

- Lima, Francisca (2001) "Los espacios públicos de Xochimilco: un recorrido a través del tiempo y sus significaciones" en: Portal Ana María, Vivir la diversidad. Identidades y cultura en dos contextos urbanos de México. Universidad Autónoma Metropolitana /CONACYT. Págs 115-126.

- Pérez, Juan Manuel (2003) Xochimilco, ayer II, Delegación XochimilcoGDF,Instituto Mora, México
- Portal, María Ana (1999) “Las fronteras simbólicas y las redes de intercambio entre los pueblos urbanos del sur del Distrito Federal" en: Aguilar Miguel Ángel, Cisneros Cesar y Nivón Eduardo. Diversidad: Aproximaciones a la cultura en la Metrópoli. Universidad Autónoma Metropolitana / Plaza y Valdés Editores. México, Págs. 19-31.

- Portal, María Ana y Sánchez, Cristina (2010) "Estrategias culturales, estructuras tradicionales y gestión social en el pueblo urbano de San Pablo Chimalpa" en Nueva antropología, vol.XXIII, núm. 73, julio-diciembre de 2010, México, Págs. 119-146

- Salles, Vania (1995) "Ideas para estudiar las fiestas religiosas: una experiencia en Xochimilco." En: Alteridades, año 5, núm. 9. Universidad Autónoma Metropolitana. Págs. 25-40.

- Sirvent, Gladys (2000) La sobrevivencia de una cultura. San Gregorio Atlapulco, Xochimilco, tesis de maestría en sociología, FCPyS, UNAM, México.

\section{Gisela Landázuri Benítez}

Pofesora-investigadora de la Universidad Autónoma Metropolitana-Xochimilco, adscrita al Departamento de Política y Cultura. Cuenta con Licenciatura y maestría en Economía, Facultad de Economía, UNAM

Maestría y doctorado en Ciencias Antropológicas, UAM- I

Ha publicado 3 libros y coordinado 8 libros colectivos además de numerosos artículos y capítulos de libro en México y en el extranjero.

\section{Liliana López Levi}

Profesora-investigadora de la Universidad Autónoma MetropolitanaXochimilco, adscrita al Departamento de Política y Cultura.

Estudió la licenciatura, maestría y doctorado en Geografía en la Facultad de Filosofía y Letras de la UNAM. Ha publicado un libro y numerosos artículos y capítulos de libro en torno a temas de cultura, imaginarios y territorio. 